\title{
Investigation of Association of Complement 5 Genetic Polymorphisms with Sepsis and Sepsis-Induced Inflammatory Responses
}

\author{
Kaidian Chen ${ }^{1, *}$ \\ Yao Lin (iD) ${ }^{1, *}$ \\ Yuchun Liu ${ }^{l, *}$ \\ Shuanglin Liao (D) ${ }^{2}$ \\ Ruoxuan Yang' \\ Jiefeng Huang' \\ Mingwei $\mathrm{Xu}$ ' \\ Junbing $\mathrm{He}$ (D) \\ 'The Intensive Care Unit, Jieyang \\ Affiliated Hospital, Sun Yat-sen \\ University, Jieyang, Guangdong, People's \\ Republic of China; ${ }^{2}$ The Intensive Care \\ Unit, The First Dongguan Affiliated \\ Hospital of Guangdong Medical \\ University, Dongguan, Guangdong, \\ People's Republic of China \\ *These authors contributed equally to \\ this work
}

Background: Complement 5 (C5) and C5a production play a pivotal role in the pathophysiology of sepsis. Strong evidence demonstrates an association of C5 gene polymorphisms with various inflammatory diseases. However, no current studies have explored the clinical relevance of C5 polymorphisms in sepsis.

Methods: Two C5 gene polymorphisms, rs17611 and rs2269067, were identified by genotyping in 636 sepsis patients and 753 controls in a Han Chinese population. C5 gene expression was detected via quantitative real-time PCR. C5a and proinflammatory cytokine production was measured by enzyme-linked immunosorbent assay. An Annexin V apoptosis assay was performed to assess cell apoptosis.

Results: Our results showed significantly lower frequencies of rs 2269067 GC/CC genotypes or $\mathrm{C}$ allele in sepsis patients than healthy controls. The frequencies of rs $17611 \mathrm{CC} / \mathrm{CT}$ genotypes or $\mathrm{C}$ allele were significantly overrepresented in both the septic shock and nonsurvivor subgroups. Patients with this sepsis-associated high-risk rs17611 C allele exhibited a significant increase in C5a, TNF- $\alpha$ and IL-6 production. However, no significant difference in $\mathrm{C} 5 \mathrm{a}$ and downstream proinflammatory cytokine production was observed among patients with different rs2269067 genotypes. In addition, in vitro experiments showed an effect of recombinant C5a on enhancing LPS-stimulated IL-1 $\beta$, IL-6 and TNF- $\alpha$ production and cell apoptosis in THP-1 monocytes.

Conclusion: The rs2269067 polymorphism conferred protection against sepsis susceptibility. The rs17611 polymorphism was associated with increased C5a production, which ultimately potentiated the secretion of downstream proinflammatory cytokines and conferred susceptibility to sepsis progression and poor prognosis.

Keywords: C5, C5a, polymorphism, sepsis, inflammation
Correspondence: Junbing He; Mingwei Xu The Intensive Care Unit, Jieyang Affiliated Hospital, Sun Yat-sen University, Tianfu Road 107, Rongcheng district, Jieyang, 522000, Guangdong Province, People's Republic of China

Email junbinghe_gmc@163.com;

mingweixu_gmc@I26.com

\section{Introduction}

Sepsis is a heterogeneous disease state arising from systemic inflammatory reactions in response to bacterial and fungal infections. ${ }^{1}$ The most common and serious symptom of sepsis is multiple organ dysfunction syndrome, which is associated with high mortality rates worldwide. ${ }^{2}$ Despite extensive progress in life support and antibiotic therapy, the mortality rate of sepsis patients worldwide remains as high as $25-30 \%$ because of the extreme heterogeneity in disease outcome, such as the heterogeneity in host hereditary susceptibility. ${ }^{3,4}$ As the most common type of genetic heterogeneity in humans, single nucleotide polymorphisms (SNPs) in genes encoding inflammatory cytokines, such as NLRP3, MCP-1 and IL-27, are 
associated with sepsis outcomes. ${ }^{5-7}$ Therefore, the identification and quantification of functional genetic variants associated with sepsis will help to exploit new genetic diagnostic and therapeutic approaches, which will improve the prognosis of patients who are susceptible to sepsis.

The complement system, a proteolytic cascade containing more than 40 proteins, generates various enzymes and active fragments involved in the modulation of immune and inflammatory responses. ${ }^{8}$ Cleavage of $\mathrm{C} 5$ generates the anaphylactic fragment C5a, which is one of the most potent proinflammatory peptides with a broad spectrum of functions, and initiates the assembly of the lytic membrane attack complex, which lyses bacteria or promotes inflammation at a sublytic level. ${ }^{9}$ $\mathrm{C} 5$ a signals mainly by binding to the $\mathrm{C} 5 \mathrm{a}$ receptor (C5aR) and modulates various biological activities involved in the pathophysiological processes of sepsis. ${ }^{10}$ There is strong evidence of excessive complement reactions in both experimental and human sepsis, as indicated by upregulated levels of $\mathrm{C} 3 \mathrm{a}, \mathrm{C} 4 \mathrm{a}$ and C5a. ${ }^{11,12}$ Nevertheless, C4- and C3-deficient mice exhibited increased susceptibility to endotoxin shock and poor outcomes after sepsis. ${ }^{13,14}$ In contrast, C6 deficiency and antibody-mediated inhibition of $\mathrm{C} 5$ obviously protected rats against sepsis-related mortality. ${ }^{15}$ Other studies indicated that blockade of C5a by antibodies could improve the pathological changes of sepsis after infusion of Escherichia coli. ${ }^{16,17}$ Although C5-deficient mice exhibited decreased susceptibility to organ dysfunction and mortality, inhibitors of C5 cleavage, C5a and C5aR have been shown to prevent sepsis-induced inflammatory responses, coagulation disorders and organ failure and to reduce mortality in a polymicrobial sepsis model. ${ }^{18-}$ ${ }^{21}$ This evidence confirms the significant role of $\mathrm{C} 5$ and its activation product, the $\mathrm{C} 5 \mathrm{a}$ anaphylatoxin, in the pathophysiological processes of sepsis.

Polymorphisms in complement components influence the risk of many diseases. ${ }^{22}$ The human $\mathrm{C} 5$ gene is located on chromosome $9 \mathrm{q} 34.1$, spans a genomic region of $79 \mathrm{~kb}$ and contains 41 exons that encode C5a (exons 1-16) and C5b (exons 17-41). ${ }^{23}$ Several single nucleotide polymorphisms (SNPs) of C5, such as rs10818488, rs3761847 and rs2269067, have been shown to be associated with the risks of various inflammation-related diseases, including systemic lupus erythematosus, rheumatoid arthritis, and proliferative diabetic retinopathy of type 2 diabetes. ${ }^{24-26}$ Another functional SNP in our study, a missense rs17611 SNP leading to a V802I change in $\mathrm{C} 5$, is responsible for changes in C5a production, resulting in susceptibility to rheumatoid arthritis and ischemic stroke and poor prognosis of pneumococcal meningitis. ${ }^{27-29}$ However, no current studies have explored the clinical relationship of C5 SNPs with the progression and clinical prognosis of sepsis.

A total of 636 sepsis patients and 753 healthy controls were enrolled in this study to investigate the potential association of two C5 genetic SNPs, rs17611 and rs2269067, with sepsis. Furthermore, we explored the potential association of C5 SNPs with the expression of C5, C5a and downstream proinflammatory cytokines (IL$1 \beta$, TNF- $\alpha$ and IL-6) to evaluate the role of C5 SNPs in proinflammatory processes during sepsis.

\section{Methods}

\section{Subject Enrollment}

This study consecutively recruited 1389 subjects of Chinese Han descent, including 636 sepsis patients in the intensive care unit (ICU) and 753 matched healthy controls in the Health Examination Center, from three regions of China between May 2017 and November 2019. Among these subjects, 343 sepsis patients and 421 healthy controls were recruited from the southern region of China (Jieyang Affiliated Hospital of Sun Yat-sen University in Jieyang city; Affiliated Hospital of Guangdong Medical University in Zhanjiang city; Longgang District People's Hospital in Shenzhen city), 108 sepsis patients and 139 controls were recruited from the central region of China (the Central Hospital in Wuhan city), and 185 sepsis patients and 193 controls were enrolled from the northern region of China (the Fourth Affiliated Hospital of Harbin Medical University in Harbin city). Sepsis was defined in accordance with the standard criteria (Sepsis-3). ${ }^{30}$ Healthy controls and patients with sepsis were excluded if they met the exclusion criteria described in our previous studies. ${ }^{5-7}$ Two milliliters of peripheral venous blood from the enrolled subjects was collected into an ethylene-diamine tetraacetic acid-containing tube for SNP genotyping within the first $12 \mathrm{~h}$ of sepsis diagnosis. Peripheral blood mononuclear cells (PBMCs) and plasma were extracted from the peripheral venous blood and stored separately at $-80{ }^{\circ} \mathrm{C}$ until analysis. Informed consent was provided by all the recruited participants or their legal representative if the patient with sepsis did not have the ability to consent. This study was approved by the hospital Ethics Committee and met the standards of the Declaration of Helsinki.

\section{DNA Extraction and C5 SNP Genotyping} Genomic DNA extraction from $200 \mu \mathrm{L}$ of peripheral venous blood was performed by using the TIANamp 
Genomic DNA Kit in accordance with the manufacturer's specifications (TIANGEN, China). Two C5 genetic SNPs, rs17611 and rs2269067, were genotyped with an iMLDRTM multiple SNP typing kit (Shanghai Tianhao Biotechnology Co., Ltd.), according to our previous studies. ${ }^{5}$ In addition, $10 \%$ of the samples were randomly selected as an independent validation group for regenotyping to monitor genotyping quality. Final analysis of the experimental data was performed on GeneMapper 4.1 (Applied Biosystems, Carlsbad, CA, USA).

\section{PBMC Isolation, RNA Extraction and Quantitative Real-Time PCR (qRT-PCR)}

The density gradient centrifugation method with Lymphoprep $^{\mathrm{TM}}$ (Axis-Shield PoCAS, Oslo, Norway) was used to isolate PBMCs. A total of 50 sepsis patients and 50 controls were selected at random for detection of $\mathrm{C} 5$ gene expression via qRT-PCR. First, total RNA was isolated from PBMCs by using TRIzol reagent and then converted into complementary DNA using the First Strand cDNA Synthesis Kit (Thermo Fisher Scientific) according to the manufacturer's specifications. Next, qRT-PCR was performed on an Applied Biosystems 7500 real-time PCR system (Applied Biosystems, USA) by using SYBR Premix Ex ${ }^{\text {TM }}$ Taq II (Takara). GAPDH was used as the housekeeping gene, and the sequences of the primers used for amplification were as follows: 5'TGGTGAAGACGCCAGTGGA-3' and 5'-GCACCGTCA AGGCTGAGAAC-3' for GAPDH and 5'-GAGCGT TGTCCCAGTATTCTAT-3' and 5'-ACACACTGTAAG AGTAGTCAGC-3' for C5. Data analysis was carried out using ABI 7500 Software v 2.3 (Applied Biosystems, USA). The expression of the $\mathrm{C} 5$ gene was evaluated using the $2^{-\Delta \Delta \mathrm{CT}}$ method.

\section{LPS and C5a Treatment Experiments}

Human THP-1 monocytes purchased from American Type Culture Collection (ATCC, USA) were incubated with 100 $\mathrm{ng} / \mathrm{mL}$ recombinant human $\mathrm{C} 5 \mathrm{a}$ protein (Sino Biological, Beijing, China), $500 \mathrm{ng} / \mathrm{mL}$ lipopolysaccharide (LPS; Sigma), or C5a plus LPS according to our and other previous studies. $^{7,31,32}$ After $16 \mathrm{~h}$ of incubation, the cell supernatants were harvested for cytokine measurement, and THP-1 cells were collected for flow cytometric analysis.

\section{Cytokine Measurements}

Plasma from the blood samples and supernatants from THP-1 cell cultures were isolated by centrifugation at low speed for cytokine measurements. Human C5a ELISA Kit II (BD Biosciences, CA, USA) was used to measure the concentration of C5a. To detect IL- $1 \beta, \mathrm{TNF}-\alpha$ and IL-6 cytokine production, we used enzyme-linked immunosorbent analysis with each specific ELISA kit (Boster Biological Technology, Wuhan, China) in accordance with the manufacturer's specifications. The absorbance was detected at $450 \mathrm{~nm}$ using a microplate reader to calculate the cytokine concentration.

\section{Flow Cytometric Analysis}

An ANXA5/Annexin V-FITC Apoptosis Detection Kit (Beyotime, China) was used to detect THP-1 cell apoptosis. At each time point, the THP-1 cells were collected and washed with PBS and then resuspended in binding buffer. Next, $195 \mu \mathrm{L}$ of cell suspension was incubated with $5 \mu \mathrm{L}$ ANXA5-FITC stock solution and $10 \mu \mathrm{L}$ propidium iodide (PI) in the dark for $15 \mathrm{~min}$ at room temperature. Flow cytometric analysis was performed immediately on a flow cytometer (Beckman Coulter Cytoflex, CA, USA).

\section{Statistical Analyses}

Statistical analyses were conducted with IBM SPSS Statistics, Version 26.0 (IBM, NY, USA). In this genedisease association study, genotype distributions of C5 SNPs were examined to identify deviations based on the assumption of Hardy-Weinberg equilibrium (HWE). Power calculations were conducted using QUANTO 1.2 software (University of Southern California, LA, USA). The Log rank test and Kaplan-Meier method were used to generate the curve of 28-day ICU survival of sepsis patients. Power calculations with a significance level of 0.05 and an odds ratio of 1.5 exhibited $99.9 \%$ power for rs 17611 and $99.4 \%$ power for rs 2269067 for detecting a relative risk difference between genotypes on the basis of our sample size. The chisquared test or Fisher's exact test was performed to determine the association of C5 SNPs with susceptibility to and progression of sepsis. The odds ratio (OR) and 95\% CI were calculated. Multivariable logistic regression analysis with adjustment for age, gender, illness severity (as measured by APACHE II score), and other potential confounding factors was performed to examine the association of C5 polymorphisms with sepsis and mortality. The false discovery rate was analyzed by the Benjamini-Hochberg procedure for multiple-testing correction. Continuous variables are presented as the mean $\pm \mathrm{SD}$ and were compared by using Student's $t$-test or the nonparametric Mann-Whitney $U$-test. $P<0.05$ was considered to indicate statistical significance. 


\section{Results}

\section{Overall Demographic and Clinical} Characteristics of the Studied Population

Table 1 presents the demographic information and clinical characteristics of both the sepsis patients (636) and healthy controls (753). The mean age of the sepsis patients was $61.90 \pm 0.70$ years, and there were more males $(421 / 215)$; these parameters were matched to those of healthy controls (mean age: $60.39 \pm 0.61$ years; $37.3 \%$ female). There was no evident difference in age or sex distribution (both $P>0.05)$. Respiratory tract infection (64.5\%) was the most common infection source, followed by abdominal infection (27.0\%). The most common pathogens identified in this study were Acinetobacter baumannii (25.3\%), followed by $P$. aeruginosa (12.4\%) and Escherichia coli (11.6\%). The case cohort consisted of 636 sepsis patients who were subdivided into the sepsis subtype $(n=351$, $55.2 \%)$ and septic shock groups $(\mathrm{n}=285,44.8 \%)$ in

Table I Clinical Characteristics of Sepsis Patients and Healthy Controls

\begin{tabular}{|c|c|c|c|}
\hline Variable & Sepsis $(n=636)$ & Control $(n=753)$ & $P$ value \\
\hline \multicolumn{4}{|l|}{ Demographics } \\
\hline Age, years, mean \pm SEM & $61.90 \pm 0.70$ & $60.39 \pm 0.61$ & 0.102 \\
\hline Male/female, number & $421 / 215$ & $472 / 281$ & 0.174 \\
\hline \multicolumn{4}{|l|}{ Sepsis status, n (\%) } \\
\hline Sepsis subtype & $35 \mathrm{I}(55.2)$ & N.A & \\
\hline Septic shock & $285(44.8)$ & N.A & \\
\hline \multicolumn{4}{|l|}{ Source of infection, $n$ (\%) } \\
\hline Respiratory tract infection & $410(64.5)$ & N.A & \\
\hline Primary bloodstream infection & $88(13.8)$ & N.A & \\
\hline Abdominal infection & $172(27.0)$ & N.A & \\
\hline Urinary tract infection & $69(10.8)$ & N.A & \\
\hline Catheter-associated infection & $48(7.5)$ & N.A & \\
\hline Brain & $47(7.4)$ & N.A & \\
\hline Trauma & $46(7.2)$ & & \\
\hline Others & $47(7.4)$ & N.A & \\
\hline \multicolumn{4}{|l|}{ Infection types, n (\%) } \\
\hline Gram-positive & $96(15.1)$ & N.A & \\
\hline Gram-negative & $333(52.4)$ & N.A & \\
\hline $\begin{array}{l}\text { Mixed Gram-negative and - } \\
\text { positive }\end{array}$ & $200(31.4)$ & N.A & \\
\hline Fungus & $143(22.5)$ & N.A & \\
\hline Negative blood culture & $32(5.0)$ & N.A & \\
\hline \multicolumn{4}{|l|}{ Pathogenic bacteria, n (\%) } \\
\hline Acinetobacter baumannii & $16 \mid(25.3)$ & N.A & \\
\hline Pseudomonas aeruginosa & $79(12.4)$ & N.A & \\
\hline Escherichia coli & 74 ( 11.6$)$ & N.A & \\
\hline Monilia albicans & $59(9.3)$ & N.A & \\
\hline Staphylococcus aureus & $53(8.3)$ & N.A & \\
\hline Klebsiella pneumoniae & $45(7.1)$ & N.A & \\
\hline Yeast sample sporophyte & $39(6.1)$ & N.A & \\
\hline Aspergillus & $25(3.9)$ & N.A & \\
\hline Others & $110(17.3)$ & N.A & \\
\hline APACHE II score, mean \pm SD & $26.7 \pm 4.5$ & N.A & \\
\hline qSOFA score, mean \pm SD & $2.5 I \pm 0.6 I$ & N.A & \\
\hline SOFA score, mean \pm SD & $8.26 \pm 4.41$ & N.A & \\
\hline 28-day mortality, n (\%) & $166(26.1)$ & N.A & \\
\hline
\end{tabular}

Abbreviations: N.A, not applicable; APACHE II, Acute Physiology and Chronic Health Evaluation II; qSOFA, quick sepsis-related organ dysfunction assessment; SOFA, sepsis-related organ dysfunction assessment. 
accordance with the previously mentioned criteria. The case cohort was further stratified into survivors $(n=470$, $73.9 \%)$ and nonsurvivors $(n=166,26.1 \%)$ according to 28 day mortality. The mean quick sepsis-related organ dysfunction assessment (qSOFA) and SOFA score in the enrolled patients with sepsis was $2.51 \pm 0.61$ and 8.26 \pm 4.41 , respectively. Other clinical features of patients with sepsis are also presented in Table 1.

\section{Distribution of C5 Genetic SNPs Frequency in Sepsis Patients and Healthy Controls}

The genotype and allele frequencies of rs17611 and rs2269067 polymorphisms are summarized in Table 2. A total of 1389 participants were successfully shown by genotyping to harbor rs17611 (636 cases and 753 controls) and recruited in this study. On the other hand, 512 cases and 702 controls were shown by genotyping to harbor rs2269067. No significant deviations from HardyWeinberg equilibrium (HWE) were identified in terms of the genotype/allele distributions of $\mathrm{C} 5$ genetic variants in the samples from sepsis patients and controls (all $P>0.05$, Additional Table 1). Our data suggested a protective role of rs2269067 GC/CC genotypes or C allele against sepsis susceptibility, as indicated by significantly lower frequencies of the $\mathrm{GC} / \mathrm{CC}$ genotypes $(\mathrm{GC}+\mathrm{CC}$ vs $\mathrm{GG}$ : $P=0.010$, $\mathrm{OR}=0.736,95 \% \mathrm{CI} 0.581-0.929)$ and $\mathrm{C}$ allele (C allele vs
G allele: $P=0.020, \mathrm{OR}=0.796,95 \%$ CI $0.656-0.964)$ in sepsis patients. After adjusting for age and gender by using multivariable logistic regression analysis, this significant finding still held $(\mathrm{GC}+\mathrm{CC}$ vs $\mathrm{GG}: P=0.011$, $\mathrm{OR}=0.737$, 95\% CI 0.583-0.932). Nevertheless, our data did not show any significant differences in the genotype/ allele distribution of the $\mathrm{C} 5$ rs $17611 \mathrm{C}>\mathrm{T}$ polymorphism between sepsis patients and controls (all $P>0.05$ ).

\section{C5 rs I76II C>T Polymorphism Conferred Susceptibility to Sepsis Progression}

For further statistical analysis, the cohort of patients was subdivided into two subgroups, namely, the sepsis subtype and septic shock subgroups, according to the previously mentioned criteria. As presented in Table 3, the frequencies of rs17611 CC/CT genotypes were significantly higher in the septic shock subgroup than in the sepsis subtype subgroup $(\mathrm{CC}+\mathrm{CT}$ vs TT: $P=0.028, \mathrm{OR}=1.460$, 95\% CI 1.041-2.042), and similar results were observed for the proportion of rs $17611 \mathrm{C}$ allele carriers ( $\mathrm{C}$ allele vs T allele: $P=0.023, \mathrm{OR}=1.295,95 \%$ CI 1.039-1.616). After multivariable logistic regression analysis with adjustment for age, gender and illness severity as measured by the APACHE II score, carriage of rs $17611 \mathrm{CC} / \mathrm{CT}$ genotypes was significantly associated with an increased risk for septic shock $(\mathrm{CC}+\mathrm{CT}$ vs TT: $P=0.018, \mathrm{OR}=1.513,95 \%$

Table 2 Genotype and Allele Frequencies Distribution of the C5 Polymorphisms in the Sepsis Patients and Healthy Controls

\begin{tabular}{|c|c|c|c|c|c|c|c|}
\hline SNP & Sepsis n (\%) & Control n (\%) & $\mathbf{P}$ & Adjusted $P^{a}$ & OR $(95 \% \mathrm{Cl})$ & Adjusted $P^{b}$ & Adjusted OR $(95 \% \mathrm{Cl})^{b}$ \\
\hline rs 17611 & & & & & & & \\
\hline CC & $118(18.6)$ & $162(21.5)$ & 0.368 & 0.507 & - & - & - \\
\hline CT & $313(49.2)$ & $351(46.6)$ & - & - & - & - & - \\
\hline TT & $205(32.2)$ & $240(31.9)$ & - & - & - & - & - \\
\hline$(\mathrm{CC}+\mathrm{CT})$ vs $\mathrm{TT}$ & $431(67.8)$ & $513(68.1)$ & 0.886 & 0.886 & $0.984(0.785,1.235)$ & 0.934 & $0.991(0.790,1.242)$ \\
\hline$(\mathrm{CT}+\mathrm{TT})$ vs $\mathrm{CC}$ & $518(81.4)$ & 591 (78.5) & 0.171 & 0.507 & $1.203(0.926,1.575)$ & 0.170 & $1.204(0.923,1.570)$ \\
\hline $\mathrm{C}$ allele & $549(43.2)$ & $675(44.8)$ & 0.380 & 0.507 & $0.935(0.804,1.086)$ & - & - \\
\hline T allele & $723(56.8)$ & $831(55.2)$ & - & - & 1.000 (reference) & - & - \\
\hline rs2269067 & & & & & & & \\
\hline GG & $325(63.5)$ & $394(56.1)$ & 0.035 & 0.046 & - & - & - \\
\hline GC & $160(3 \mid .2)$ & $266(37.9)$ & - & - & - & - & - \\
\hline CC & $27(5.3)$ & $42(6.0)$ & - & - & - & - & - \\
\hline$(G G+G C)$ vs $C C$ & $485(94.7)$ & $660(94.0)$ & 0.598 & 0.598 & $1.143(0.6938,1.850)$ & 0.610 & $1.139(0.692,1.874)$ \\
\hline$(\mathrm{GC}+\mathrm{CC})$ vs $\mathrm{GG}$ & $187(36.5)$ & $308(43.9)$ & 0.010 & 0.040 & $0.736(0.58 \mathrm{I}, 0.929)$ & 0.011 & $0.737(0.583,0.932)$ \\
\hline $\mathrm{G}$ allele & $810(79.1)$ & $1054(75.1)$ & - & - & 1.000 (reference) & - & - \\
\hline$C$ allele & $214(20.9)$ & $350(24.9)$ & 0.020 & 0.040 & $0.796(0.656,0.964)$ & - & - \\
\hline
\end{tabular}

Notes: ${ }^{a}$ False discovery rate-adjusted P-value for multiple hypotheses testing by using the Benjamini-Hochberg method; ${ }^{\mathrm{b}}$ adjusted for age and gender by using multivariable logistic regression analysis.

Abbreviations: OR, odds ratio; $95 \% \mathrm{Cl}, 95 \%$ confidence interval. 


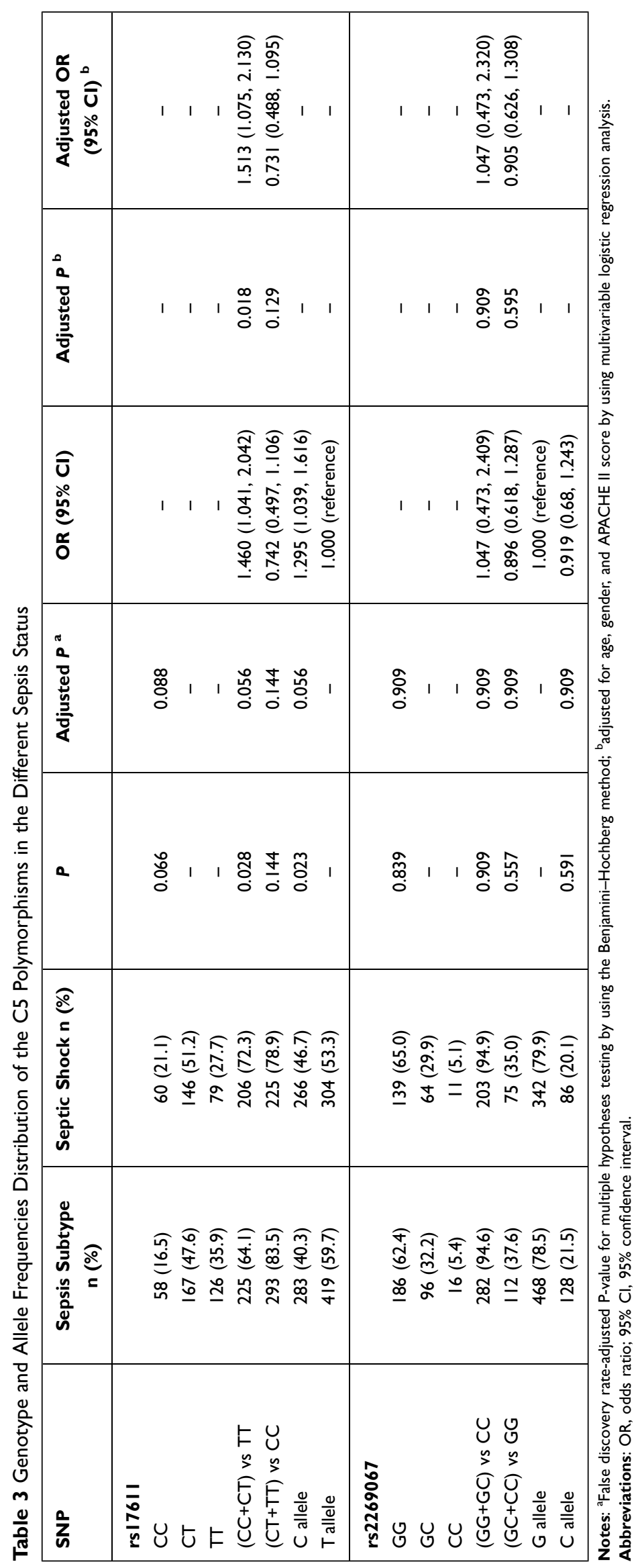


CI 1.075-2.130). However, no significant differences in the genotype/allele distribution of the C5 rs2269067 G>C polymorphism were observed between the two subgroups.

\section{SNP Association with Mortality Rate}

The positions of two C5 genetic polymorphisms, rs2269067 within the intron near exon 30 and rs17611 within exon 19 of the gene, are shown in Figure 1A. Next, the study cohort of patients was subdivided into two subgroups based on the 28-day mortality rate to evaluate the SNP association with the mortality rate (Table 4). A statistically significant difference in the genotype/allele frequencies of rs17611, but not those of rs2269067, was observed between the survivors and non-survivors

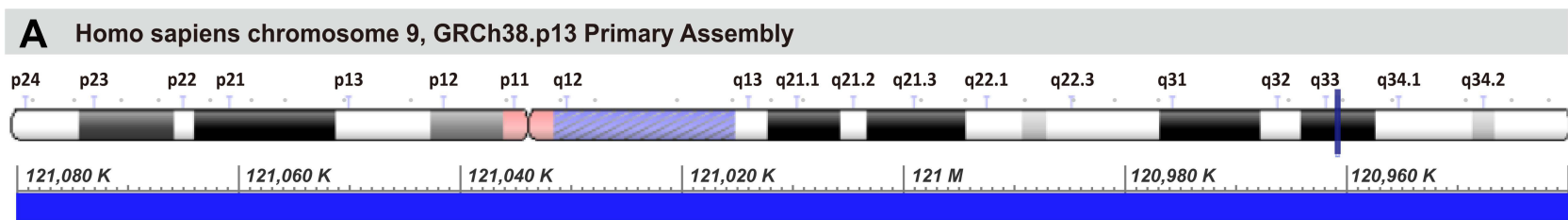

NM_001317163.2

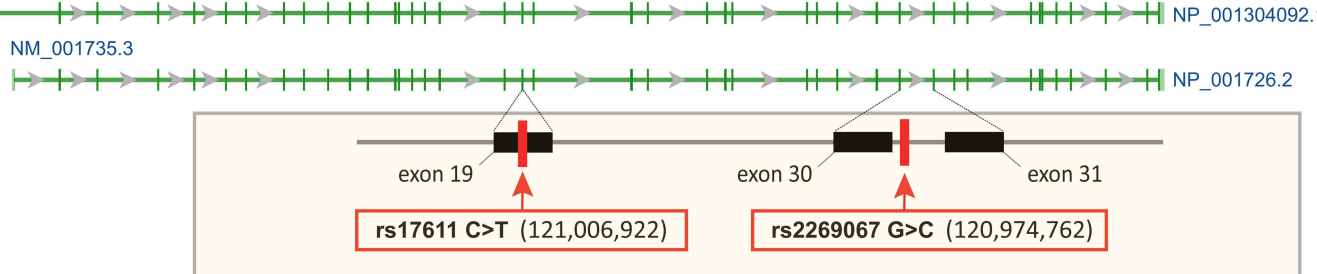

B

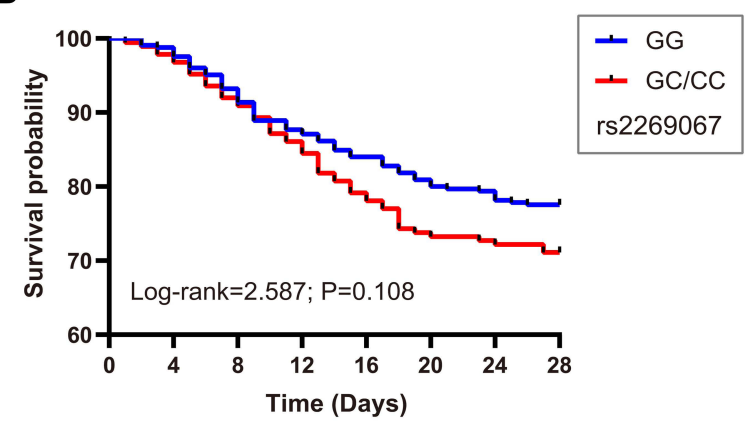

D

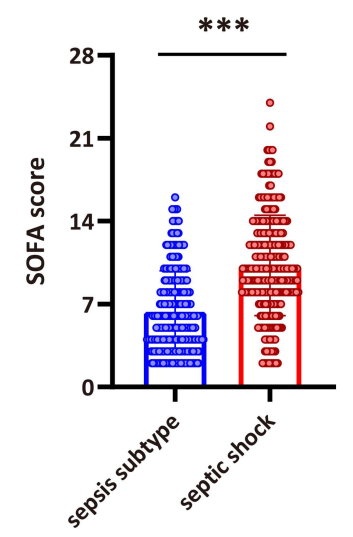

E

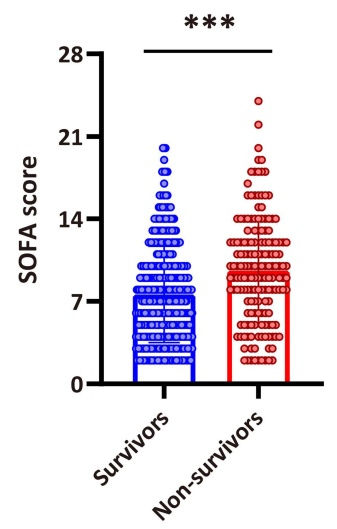

C

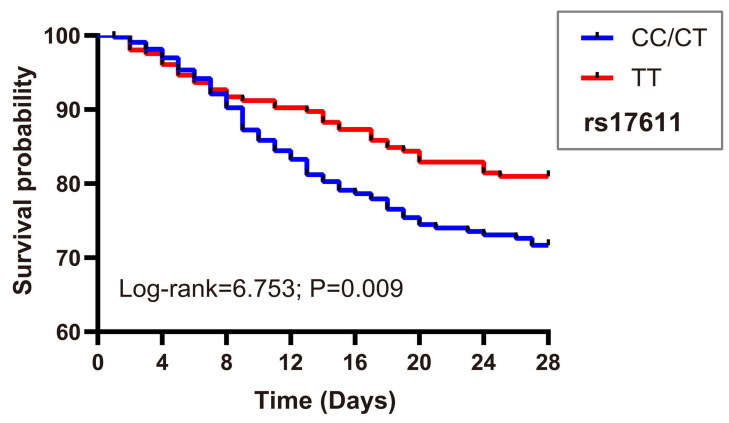

$\mathbf{F}$

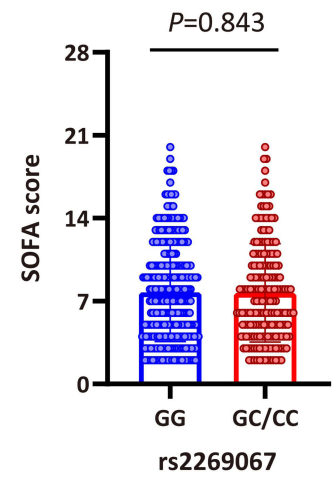

G

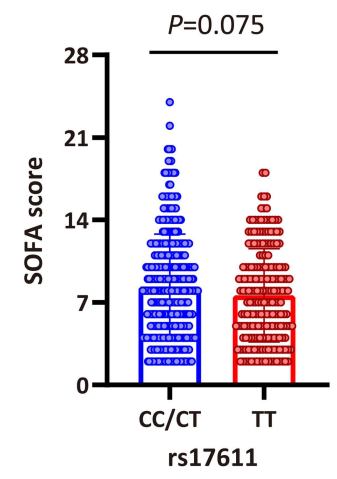

Figure I The location of rs2269067 and rs 176 II polymorphisms in C5 gene and their effect on 28-day survival of sepsis patients. (A) The human C5 gene is located on chromosome 9q34.I (I20,952,335-121,050,275) and contains 41 exons according to the GRCh38.pI3 primary assembly. The green bar represents the exons. In the visual, the miss-sense rs 176 I I C>T polymorphism is located within the exon 19 of C5 gene and causes a V802I change in C5, while rs2269067 G>C polymorphism is located within the intron near to exon 30; (B and C) the effect of rs2269067 and rs I76II on the 28-day survival of sepsis patients was evaluated by Kaplan-Meier survival analysis; (D and $\mathbf{E}$ ) the sepsis-related organ dysfunction assessment (SOFA) score in sepsis patients; (F and $\mathbf{G})$ the correlation of C5 genetic polymorphisms with SOFA score in sepsis patients. Values of relative expression levels are shown as mean $\pm S D ; * * * P<0.00$ I. 


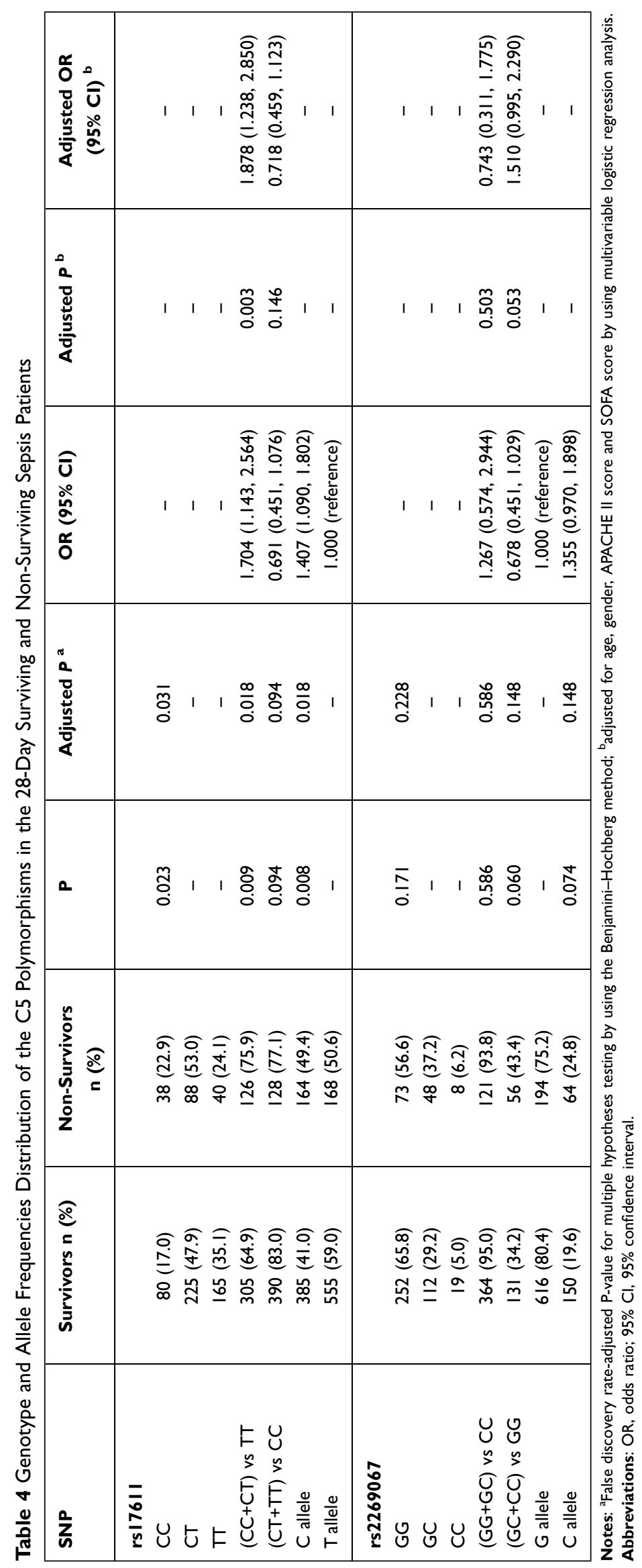


(rs17611 $\mathrm{CC}+\mathrm{CT}$ vs TT: $P=0.009, \mathrm{OR}=1.704,95 \% \mathrm{CI}$ 1.143-2.564; $\mathrm{C}$ allele vs $\mathrm{T}$ allele: $P=0.008, \mathrm{OR}=1.407$, 95\% CI 1.090-1.802). We obtained similar results also in a multivariable logistic regression analysis adjusted for age, gender, APACHE II score and SOFA score (rs17611 $\mathrm{CC}+\mathrm{CT}$ vs TT: $P=0.003, \quad \mathrm{OR}=1.878,95 \%$ CI 1.238 2.850). Kaplan-Meier survival analysis in Figure $1 \mathrm{~B}$ and $\mathrm{C}$ showed that 28-day survival was much worse in patients with the rs17611 CC/CT genotype than in those with the TT genotype (log-rank=6.753, $P=0.009)$. However, no significant difference was observed in patients with the C5 rs2269067 G>C polymorphism (log-rank=2.587, $P=0.108$ ).

We further evaluated the possible correlation of $\mathrm{C} 5$ genetic polymorphisms with SOFA score. Our data showed that SOFA score in septic shock or non-survivor subgroups was significantly higher than that in sepsis subtype or survivor subgroups (both $\mathrm{P}<0.001$; Figure 1D and E). When stratified by the different genotypes of C5 polymorphisms, no significant difference in SOFA score was observed between different genotypes of rs2269067 $(P=0.843$; Figure $1 \mathrm{~F})$. SOFA score in sepsis patients with rs17611 CC/CT genotypes appeared to be higher than that in TT genotype carriers, despite no proven statistical significance ( $P=0.075$; Figure $1 \mathrm{G})$. Besides, we performed an analysis of pathogen class by $\mathrm{C} 5$ polymorphisms in sepsis patients. None of the studied SNPs revealed significant associations with the presence of each pathogen (eg, Acinetobacter baumannii, P. aeruginosa, Escherichia coli, Monilia albicans, Staphylococcus aureus, Klebsiella pneumoniae, Yeast sample sporophyte and Aspergillus) (All $P>0.05$; Additional Table 2).

\section{The Influence of C5 Genetic SNPs on C5 Gene Expression and C5a Production}

The aforementioned results indicated the clinical relevance of C5 genetic SNPs in susceptibility to and progression of sepsis. To explore the biological functions of these two C5 genetic SNPs, we further evaluated their effect on $\mathrm{C} 5$ gene expression in PBMCs and C5a levels in plasma from sepsis patients and healthy controls with a known SNP genotype. $\mathrm{C} 5$ gene expression and $\mathrm{C} 5 \mathrm{a}$ production levels in sepsis patients were obviously higher than those in healthy controls, and $\mathrm{C} 5 \mathrm{a}$ production levels increased with sepsis progression (Figure 2A-F). Furthermore, the expression of $\mathrm{C} 5$, but not C5a, was obviously increased in patients with the rs 2269067 GG genotype compared with patients with the $\mathrm{GC} / \mathrm{CC}$ genotype (Figure $2 \mathrm{G}$ and $\mathrm{H}$ ). With regard to the rs17611 polymorphism, the expression of C5a, but not C5, was significantly upregulated in sepsis
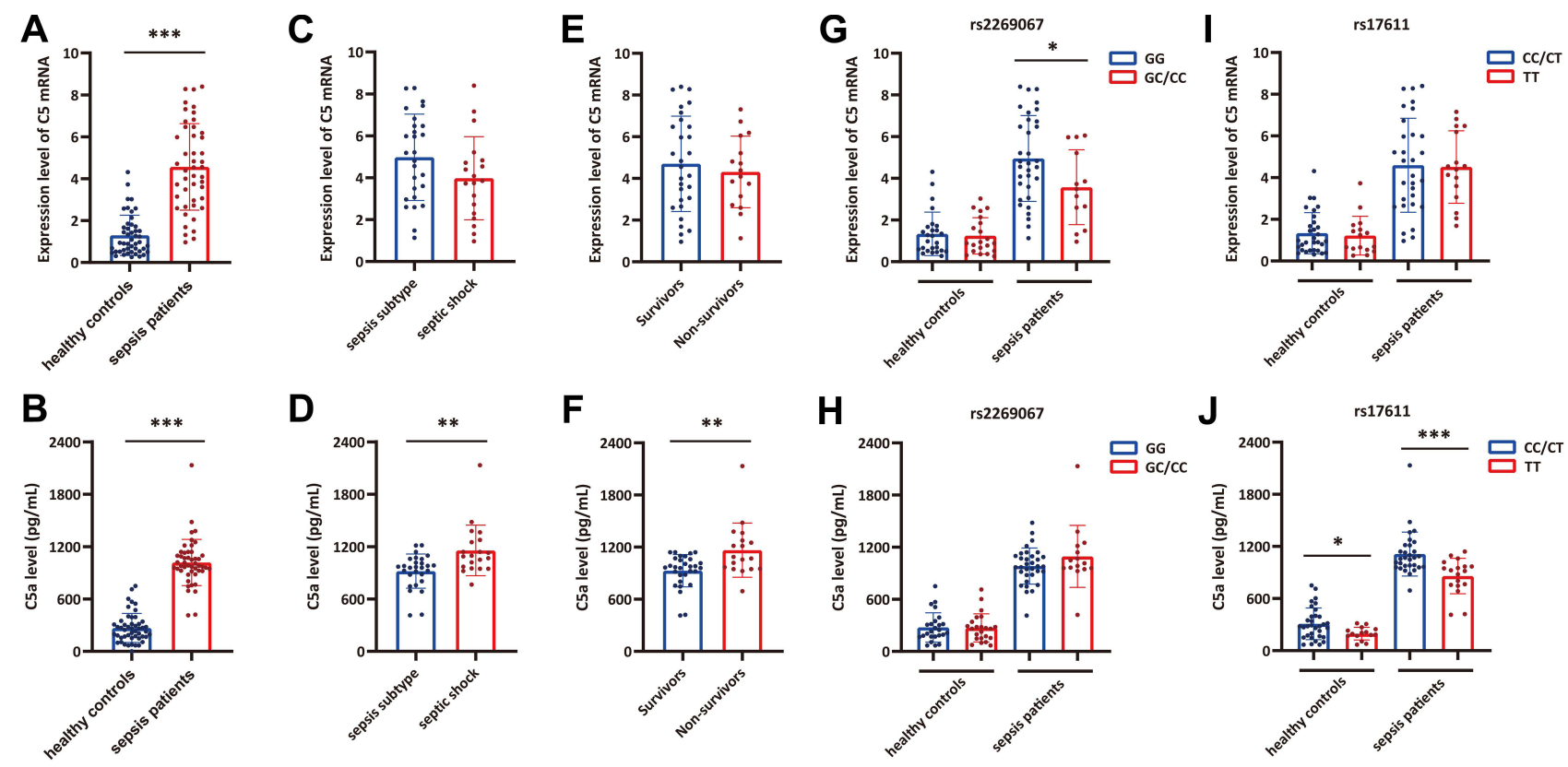

Figure 2 The influence of $C 5$ genetic polymorphisms on $C 5$ gene expression and C5a production in sepsis patients and healthy controls. (A and $\mathbf{B})$ The $C 5$ gene expression and C5a production levels in sepsis patients and healthy controls; (C and $\mathbf{D})$ the $\mathrm{C5}$ gene expression and C5a production levels in sepsis subtype and septic shock subgroups; (E and $\mathbf{F})$ the $\mathrm{C5}$ gene expression and C5a production levels in survivor and non-survivor subgroups; ( $\mathbf{G}$ and $\mathbf{H})$ the distribution of $\mathrm{C5}$ and $\mathrm{C5}$ a expression in individuals with different rs 2269067 genotypes; (I and $\mathbf{J})$ the distribution of $C 5$ and $C 5$ a expression in individuals with different rs I $76 \mathrm{II}$ genotypes. Values of relative expression levels are shown as mean $\pm S D ; * P<0.05$, $* * P<0.01$, $* * * P<0.001$. 
patients with the $\mathrm{CC} / \mathrm{CT}$ genotype compared with those with the TT genotype (Figure 2I and J).

\section{The Influence of C5 Genetic SNPs on Inflammatory Cytokine Production}

As presented in Figure 3, the secretion of downstream proinflammatory cytokines (IL-1 $\beta$, TNF- $\alpha$ and IL-6) was measured in the plasma from sepsis cases and controls with different genotypes of C5 genetic SNPs. Our data suggested that IL-1 $\beta$, TNF- $\alpha$ and IL- 6 expression were significantly upregulated in sepsis patients compared with healthy controls (Figure 3A-C). Patients in the septic shock group exhibited higher expression levels of these inflammatory cytokines, except for IL-6, than those in the sepsis subtype group (Figure 3D-F). When the sepsis patients were subdivided into two subgroups based on 28day mortality, the IL- 6 and TNF- $\alpha$ expression levels were significantly increased in the nonsurvivors compared with the survivors (Figure 3G-I). We further assessed the effect of $\mathrm{C} 5$ genetic SNPs on inflammatory cytokine production. No significant differences in proinflammatory cytokine (IL-1 $\beta$, TNF- $\alpha$ and IL-6) production were observed among the sepsis patients or controls with different genotypes of the rs $2269067 \mathrm{G}>\mathrm{C}$ polymorphism (Figure $3 \mathrm{~J}$ and L). Patients with the rs $17611 \mathrm{CC} / \mathrm{CT}$ genotypes exhibited a significant increase in TNF- $\alpha$ and IL-6 production compared with those with the TT genotype (Figure $3 \mathrm{M}-\mathrm{O}$ ).

\section{C5a Enhances LPS-Induced Inflammation-Related Cytokine Production and Cell Apoptosis}

A further experiment was performed to assess the role of C5a in LPS-induced inflammation-related cytokine production and apoptosis in THP-1 monocytes. Cells were
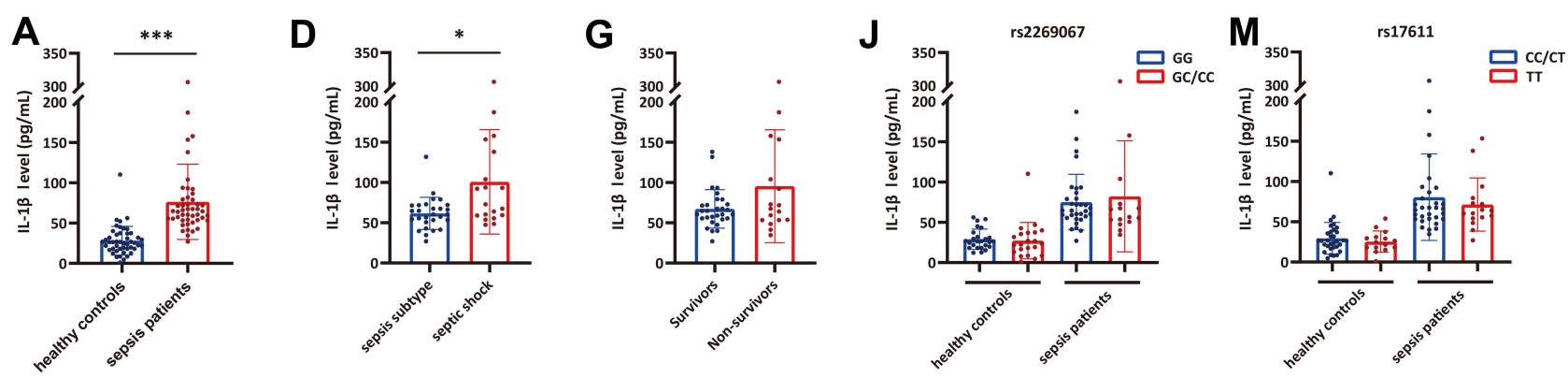
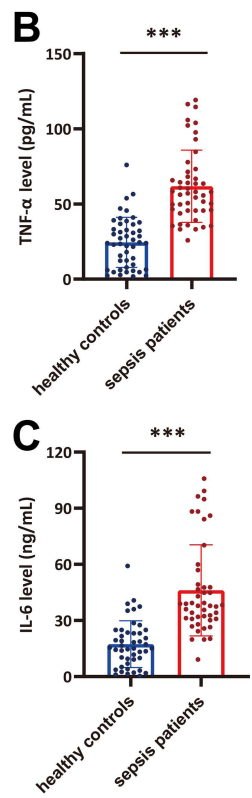

E

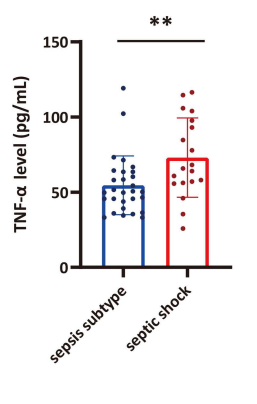

$\mathbf{F}$

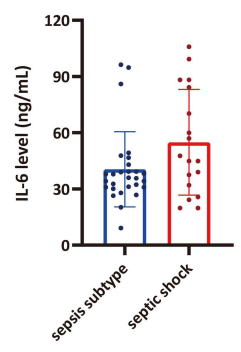

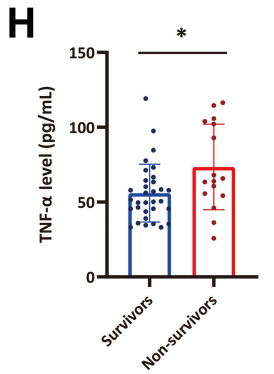

K

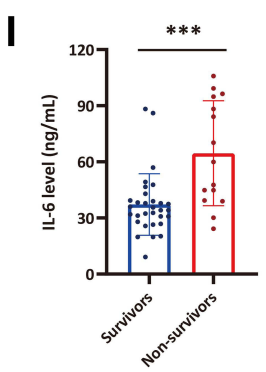

L
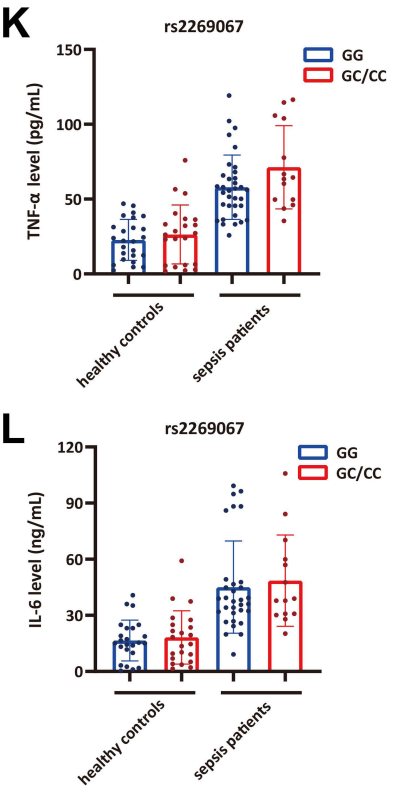
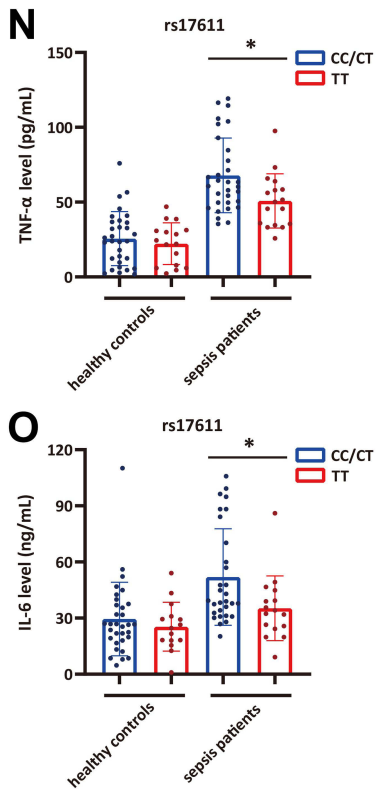

Figure 3 The influence of C5 genetic SNPs on inflammatory cytokine production in sepsis patients and healthy controls. (A-C) The IL-I $\beta$, TNF- $\alpha$ and IL-6 plasma levels in sepsis patients and healthy controls; (D-F) the IL-I $\beta$, TNF- $\alpha$ and IL-6 plasma levels in sepsis subtype and septic shock subgroups; (G-I) the IL-I $\beta$, TNF- $\alpha$ and IL-6 plasma levels in survivor and non-survivor subgroups; (J-L) the distribution of IL-I $\beta$, TNF- $\alpha$ and IL-6 plasma levels in individuals with different rs2269067 genotypes; (M-O) the distribution of IL-I $\beta$, TNF- $\alpha$ and IL- 6 plasma levels in individuals with different rs I 76II genotypes. Values of relative expression levels are shown as mean \pm SD; $* P<0.05$, $* * P<0.01$, **** $<0.001$. 
stimulated with C5a, LPS, or both for $16 \mathrm{~h}$ in vitro. As presented in Figure 4, the data showed an effect of C5a on enhancing LPS-stimulated IL-1 $\beta$, TNF- $\alpha$ and IL- 6 production. Nevertheless, C5a treatment did not exert any significant effect on the production of these inflammatory cytokines without LPS stimulation. In addition, the apoptotic rates of THP-1 monocytes stimulated with C5a plus LPS were significantly higher than those of THP-1 monocytes stimulated with C5a or LPS alone.

\section{Discussion}

Proinflammatory immune responses play pivotal roles in the pathophysiology of sepsis. ${ }^{33}$ Several lines of evidence have demonstrated a significant role of the complement system in inflammatory processes and various inflammation-related diseases, such as sepsis. ${ }^{34,35}$ Nevertheless, the clinical association of genetic SNPs in the complement system with sepsis has not been well verified. In this study, we attempted to explore, for the first time, the clinical relevance of two C5 genetic SNPs, rs2269067 and rs17611, with susceptibility to and progression of sepsis. Our data showed that the GC/CC genotypes or $\mathrm{C}$ allele of rs2269067 exhibited a trend of a protective effect against susceptibility to sepsis, while CC/CT genotypes or C allele of rs17611 conferred susceptibility to sepsis progression and poor prognosis. Functional experiments demonstrated that the rs2269067 G>C
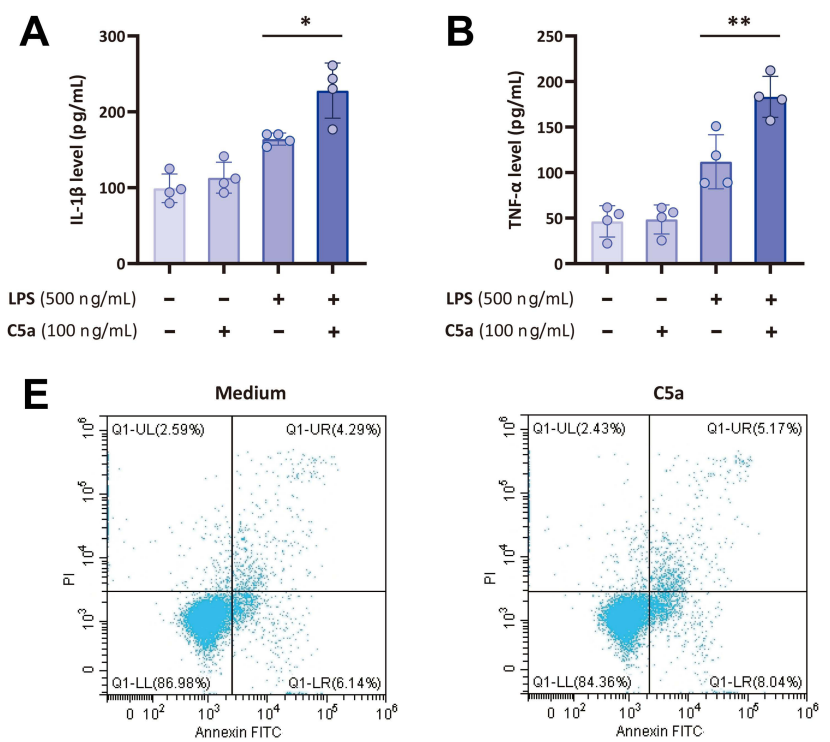

polymorphism resulted in a significant increase in C5 expression in sepsis patients but exerted no significant effect on C5a and downstream inflammatory cytokine production. Furthermore, the rs $17611 \mathrm{C}>\mathrm{T}$ polymorphism within exon 19 of the $\mathrm{C} 5$ gene might affect $\mathrm{C} 5 \mathrm{a}$ production and cause changes in proinflammatory cytokine production, which ultimately lead to sepsis progression and poor prognosis.

Complement is composed of over 45 soluble and membrane-binding proteins, which perform a variety of biological functions and are strictly controlled by various regulatory proteins. ${ }^{36}$ The initial activation of the complement cascade occurs via the classical, alternative, and lectin pathways, which converge at the third component (C3), leading to the production of effectors that exacerbate inflammatory cascade responses by $\mathrm{C} 3 \mathrm{a}$ or $\mathrm{C} 5 \mathrm{a}$, eliminate microbial intruders by $\mathrm{C} 3 \mathrm{~b}$ opsonization, and lyse susceptible pathogenic microorganisms by the membrane attack complex (MAC; C5b-9 complex). ${ }^{34}$ Sepsis is associated with a strong activation complement system with the subsequent generation of various strong proinflammatory peptides, such as the C3a and C5a anaphylatoxins, leading to organ dysfunction and death. As a small complement $\mathrm{C} 5$ activation fragment, C5a anaphylatoxin, causes the activation of PMNs and macrophages via the $\mathrm{C} 5 \mathrm{a} \cdot \mathrm{C} 5 \mathrm{aR} 1$ interaction, leading to the rapid generation of chemotaxis factors, chemokines,
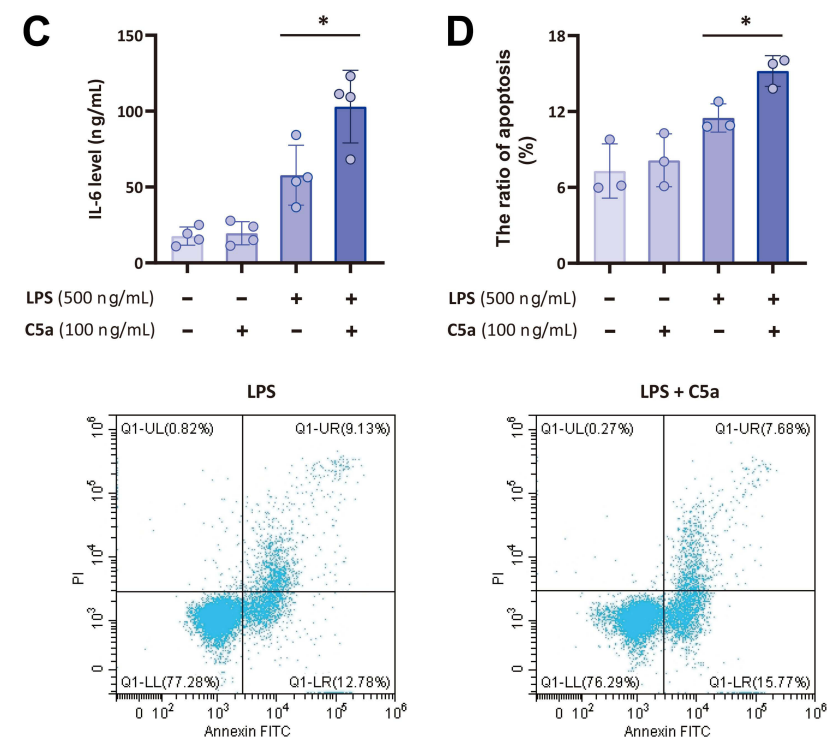

Figure $4 \mathrm{C} 5 \mathrm{a}$ enhances LPS-induced inflammatory cytokine production and cell apoptosis. THP-I monocytes were stimulated with $\mathrm{C5a}(100 \mathrm{ng} / \mathrm{mL})$, LPS (500 ng/mL), or C5a plus LPS for $16 \mathrm{~h}$ in vitro. (A-C) The supernatant concentrations of inflammatory cytokines (IL-I $\beta$, TNF- $\alpha$ and IL-6) were measured by ELISA; (D and E) the apoptosis of THP-I monocytes stimulated with C5a, LPS, or C5a plus LPS was also measured by using annexin-V-FITC/PI staining on a flow cytometer. Values of relative expression levels are shown as mean $\pm \mathrm{SD} ; * P<0.05, * * P<0.01$. 
proinflammatory cytokines and harmful oxygen free radicals in sepsis. ${ }^{10,37}$ Inhibition of C5a and its receptor C5aR1 has been demonstrated to ameliorate the inflammatory response and improve organ function and survival in a mouse sepsis model. ${ }^{38,39}$ Thus, we first evaluated the clinical interrelation of $\mathrm{C} 5$ and $\mathrm{C} 5 \mathrm{a}$ expression with sepsis. Our data indicated that $\mathrm{C} 5 \mathrm{a}$, but not $\mathrm{C} 5$, could serve as an indicator of sepsis severity and poor prognosis, as its expression was significantly upregulated with septic shock and death, which was consistent with previous studies. Vollrath et al reported that increased C5a expression might serve as an effective diagnostic marker for the development of sepsis or septic complications after trauma. ${ }^{40}$ Other studies indicated C5a levels as an independent predictor for the disease outcome of sepsis. ${ }^{41,42}$ These lines of evidence demonstrated pivotal roles of C5a in sepsis pathophysiology.

Recent studies identifying the responsible genetic variants have demonstrated that several C5 SNPs influence C5 mRNA expression and C5a production and confer susceptibility to various inflammatory diseases. ${ }^{24-29} \mathrm{Xu}$ et al found that the GG genotype of the C5 rs2269067 polymorphism resulted in elevated C5 expression and patient predisposition to acute anterior uveitis. ${ }^{43}$ Other studies indicated that rs17611, a missense polymorphism leading to a V802I change in C5, was associated with elevated C5a production, increased susceptibility to large artery atherosclerosis stroke, and poor cardiovascular outcome. ${ }^{44,45}$ However, no current studies have explored the clinical relationship of C5 SNPs with the susceptibility and clinical prognosis of sepsis. In this study, our results indicated that rs2269067 polymorphism exerted protective effect against sepsis susceptibility, as indicated by significantly lower frequencies of the $\mathrm{GC} / \mathrm{CC}$ genotypes or $\mathrm{C}$ allele in sepsis patients than in healthy controls. Nevertheless, we did not observe any differences in C5a production among different genotypes of rs 2269067 . With regard to the rs $17611 \mathrm{C}>\mathrm{T}$ polymorphism, the frequencies of the $\mathrm{CC} / \mathrm{CT}$ genotypes or the $\mathrm{C}$ allele were overrepresented in both the septic shock and non-survivor subgroups. The patients with rs17611 CC/CT genotypes exhibited a significant increase in $\mathrm{C} 5 \mathrm{a}$ production, but not C5 expression. Consistently, Giles et al discovered that the rs17611 $\mathrm{C}>\mathrm{T}$ polymorphism conferred a state of inflammation in arthritic joints by impacting $\mathrm{C} 5$ turnover and accelerating the generation of the proinflammatory product $\mathrm{C} \mathrm{a}^{27}$ Based on these evidences, we inferred that upregulation of $\mathrm{C} 5 \mathrm{a}$ production caused by rs17611
$\mathrm{C}>\mathrm{T}$ polymorphism exerted significant role in sepsisinduced inflammatory response and patients' susceptibility to sepsis progression and poor prognosis.

$\mathrm{C} 5 \mathrm{a}$, as one of the most potent inflammatory peptides, exerts its effects on various inflammatory cells by binding to $\mathrm{C} 5 \mathrm{aR}$ and $\mathrm{C} 5 \mathrm{~L} 2$, leading to exacerbated proinflammatory responses, apoptosis and multiorgan dysfunction in sepsis. ${ }^{46,47}$ Strong evidence demonstrates that C5a accelerates the generation and release of proinflammatory cytokines, such as IL- $1 \beta$, TNF- $\alpha$, IL- 6 and MCP-1, from monocytes, macrophages and endothelial cells to create a cytokine storm. ${ }^{48}$ Furthermore, C5a activates mitogenactivated protein kinases (MAPKs) and extracellular signal-regulated kinase $1 / 2$ signaling pathways, which results in the activation of transcription factors, leading to the secretion of various chemokines and cytokines. ${ }^{32,46}$ Blockade of either $\mathrm{C} 5 \mathrm{a}$ or $\mathrm{C} 5 \mathrm{aR}$ contributed to over $75 \%$ suppression of cytokine storms. ${ }^{39,49}$ Our results exhibited an effect of recombinant $\mathrm{C} 5 \mathrm{a}$ on enhancing LPSstimulated IL-1 $\beta$, TNF- $\alpha$ and IL- 6 production and cell apoptosis, which was consistent with previous studies. Riedemann et al discovered that C5a promoted LPSstimulated IL-6 production through the activation of MAPK pathways. ${ }^{50}$ Other studies demonstrated that the complement protein $\mathrm{C} 5 \mathrm{a}$ amplified monocyte proinflammatory responses and potentiated IL- $1 \beta$, IL- $1 \alpha$ and TNF- $\alpha$ production in LPS-stimulated human monocytic cells. ${ }^{51,52}$ Given the evidence indicating a significant role of $\mathrm{C} 5 \mathrm{a}$ in the proinflammatory response after sepsis, we further detected the IL-1 $\beta$, TNF- $\alpha$ and IL- 6 expression levels in PBMCs from sepsis patients to evaluate whether these C5 polymorphisms ultimately had a genetic effect on the production of proinflammatory cytokines. The IL-6 and TNF- $\alpha$ levels were observed to be significantly elevated in sepsis patients carrying the rs $17611 \mathrm{CC} / \mathrm{CT}$ genotype, indicating that the sepsis-associated high-risk $\mathrm{C}$ allele might increase the secretion of these proinflammatory cytokines via C5a production, thereby leading to the progression of sepsis. With regard to the rs2269067 G>C polymorphism, no significant difference in IL- $1 \beta$, TNF- $\alpha$ and IL-6 production was observed among sepsis patients or controls with different genotypes.

Several limitations should be taken into account in the present study. First, although the rs $2269067 \mathrm{G}>\mathrm{C}$ polymorphism was notably associated with sepsis susceptibility, it exerted no significant effect on C5a, IL-1 $\beta$, TNF- $\alpha$ and IL-6 production in sepsis patients. Further study is required to identify the role of this polymorphism in $\mathrm{C} 5$ gene 
expression and sepsis. Second, it remains possible that the pre-existing conditions in sepsis patients might influence the genetic results of C5 SNPs on sepsis, even though we excluded patients with several pre-existing diseases to increase sample homogeneity. Third, the present study was conducted only in a Chinese Han population with a relatively small sample size. Thus, one should be especially vigilant and careful when generalizing these findings to other ethnic populations. Besides, previous studies have indicated a significant role of $\mathrm{C} 5$ as well as its genetic polymorphisms in host-pathogen interactions. ${ }^{29,53}$ The possible association of C5 SNPs with the presence of pathogens in sepsis patients may be linked with the subject's predisposition to develop the disease itself. Although the studied SNPs revealed no significant associations with the presence of each pathogen, it might potentially make a possible difference in the genetic results of C5 SNPs on sepsis in this study. Further studies with larger and multiethnic populations of subjects are required to validate our findings.

\section{Conclusions}

This study suggested that the rs $2269067 \mathrm{G}>\mathrm{C}$ polymorphism of $\mathrm{C} 5$ gene conferred protection against susceptibility to sepsis in a Chinese Han population. Furthermore, another C5 functional polymorphism, the rs17611 C-to-T mutation, significantly affected susceptibility to sepsis progression and poor prognosis rather than sepsis onset. This sepsis-associated highrisk $\mathrm{C}$ allele of rs17611 potentiated the production of $\mathrm{C} 5 \mathrm{a}$ and the secretion of downstream proinflammatory cytokines. Our findings may, to some extent, elucidate the heterogeneity of clinical outcomes in sepsis patients.

\section{Data Sharing Statement}

All data generated or analyzed during this study are included in this published article.

\section{Ethics Approval and Consent to Participate}

All experiments on human subjects were conducted in accordance with the Declaration of Helsinki. This study was approved by the Ethical Committee of Jieyang Affiliated Hospital of Sun Yat-sen University, the Affiliated Hospital of Guangdong Medical University, the Central Hospital of Wuhan and the Second Affiliated Hospital of Harbin Medical University, and written informed consent was obtained from all the healthy volunteers and patients.

\section{Author Contributions}

All authors made a significant contribution to the work reported, whether that is in the conception, study design, execution, acquisition of data, analysis and interpretation, or in all these areas; took part in drafting, revising or critically reviewing the article; gave final approval of the version to be published; have agreed on the journal to which the article has been submitted; and agree to be accountable for all aspects of the work.

\section{Funding}

This work was supported by the Science and Technology Planning Project of Jieyang City (YLWS043), the Natural Science Foundation of Guangdong Province (2020A1515010109, 2021A1515010871), and the Guangdong Province Science and Technology Special Fund of Major Projects and Task List in Jieyang City (xgfy021).

\section{Disclosure}

The authors declare that they have no competing interests.

\section{References}

1. Hotchkiss RS, Sherwood ER. Immunology. Getting sepsis therapy right. Science. 2015;347(6227):1201-1202. doi:10.1126/science. aaa8334

2. Bosurgi R. Sepsis: a need for new solutions. Lancet Infect Dis. 2015;15(5):498-499. doi:10.1016/S1473-3099(15)70030-7

3. Cohen J, Vincent JL, Adhikari NK, et al. Sepsis: a roadmap for future research. Lancet Infect Dis. 2015;15:581-614. doi:10.1016/S14733099(15)70112-X

4. Lu H, Wen D, Wang X, et al. Host genetic variants in sepsis risk: a field synopsis and meta-analysis. Crit Care. 2019;23(1):26. doi:10.1186/s13054-019-2313-0

5. Lu F, Chen H, Hong Y, et al. A gain-of-function NLRP3 3'-UTR polymorphism causes miR-146a-mediated suppression of NLRP3 expression and confers protection against sepsis progression. Sci Rep. 2021;11(1):13300. doi:10.1038/s41598-021-92547-8

6. He J, Chen Y, Lin Y, et al. Association study of MCP-1 promoter polymorphisms with the susceptibility and progression of sepsis PLoS One. 2017;12(5):e0176781. doi:10.1371/journal.pone.0176781

7. He J, Zhang Q, Zhang W, et al. The interleukin-27-964A $>$ G polymorphism enhances sepsis-induced inflammatory responses and confers susceptibility to the development of sepsis. Crit Care. 2018;22 (1):248. doi:10.1186/s13054-018-2180-0

8. Romano R, Giardino G, Cirillo E, Prencipe R, Pignata C. Complement system network in cell physiology and in human diseases. Int Rev Immunol. 2021;40(3):159-170. doi:10.1080/ 08830185.2020.1833877

9. Guo RF, Ward PA. Role of C5a in inflammatory responses. Annu Rev Immunol. 2005;23:821-852. doi:10.1146/annurev.immunol.23.021 704.115835

10. Zetoune FS, Ward PA. Role of complement and histones in sepsis. Front Med. 2020;7:616957. doi:10.3389/fmed.2020.616957

11. Ward PA. The dark side of C5a in sepsis. Nat Rev Immunol. 2004;4 (2):133-142. doi:10.1038/nri1269 
12. Helling H, Stephan B, Pindur G, Prantl L, Jung EM, Jung F. Coagulation and complement system in critically ill patients. Clin Hemorheol Microcirc. 2015;61(2):185-193. doi:10.3233/CH-151993

13. Fischer MB, Prodeus AP, Nicholson-Weller A, et al. Increased susceptibility to endotoxin shock in complement C3- and C4-deficient mice is corrected by $\mathrm{C} 1$ inhibitor replacement. J Immunol. 1997;159 (2):976-982.

14. Prodeus AP, Zhou X, Maurer M, Galli SJ, Carroll MC. Impaired mast cell-dependent natural immunity in complement C3-deficient mice. Nature. 1997;390(6656):172-175. doi:10.1038/36586

15. Buras JA, Rice L, Orlow D, et al. Inhibition of C5 or absence of C6 protects from sepsis mortality. Immunobiology. 2004;209 (8):629-635. doi:10.1016/j.imbio.2004.09.004

16. Hangen DH, Bloom RJ, Stevens JH, et al. Adult respiratory distress syndrome. A live E coli septic primate model. Am J Pathol. 1987;126:396-400.

17. Stevens JH, O'Hanley P, Shapiro JM, et al. Effects of anti-C5a antibodies on the adult respiratory distress syndrome in septic primates. J Clin Invest. 1986;77:1812-1816. doi:10.1172/JCI112506

18. Nieuwenhuijzen GA, Meyer MP, Hendriks T, Goris RJ. Deficiency of complement factor C5 reduces early mortality but does not prevent organ damage in an animal model of multiple organ dysfunction syndrome. Crit Care Med. 1995;23(10):1686-1693. doi:10.1097/ 00003246-199510000-00013

19. Keshari RS, Silasi R, Popescu NI, et al. Inhibition of complement C5 protects against organ failure and reduces mortality in a baboon model of Escherichia coli sepsis. Proc Natl Acad Sci U S A. 2017;114(31):E6390-E6399. doi:10.1073/pnas.1706818114

20. Czermak BJ, Sarma V, Pierson CL, et al. Protective effects of C5a blockade in sepsis. Nat Med. 1999;5(7):788-792. doi:10.1038/10512

21. Ward PA. The harmful role of c5a on innate immunity in sepsis. J Innate Immun. 2010;2(5):439-445. doi:10.1159/000317194

22. Harris CL, Heurich M, Rodriguez de Cordoba S, Morgan BP. The complotype: dictating risk for inflammation and infection. Trends Immunol. 2012;33(10):513-521. doi:10.1016/j.it.2012.06.001

23. Arnaout R, Al Shorbaghi S, Al Dhekri H, et al. C5 complement deficiency in a Saudi family, molecular characterization of mutation and literature review. $J$ Clin Immunol. 2013;33(4):871-875. doi:10.1007/s10875-013-9872-7

24. Zervou MI, Vazgiourakis VM, Yilmaz N, et al. TRAF1/C5, eNOS, C1q, but not STAT4 and PTPN22 gene polymorphisms are associated with genetic susceptibility to systemic lupus erythematosus in Turkey. Hum Immunol. 2011;72(12):1210-1213. doi:10.1016/j. humimm.2011.09.003

25. Huang SC, Hua DJ, Sun QQ, Zhang LN, Cen H, Zhou L. Associations of TRAF1/C5 rs10818488 and rs3761847 polymorphisms with genetic susceptibility to rheumatoid arthritis: a case-control study and updated meta-analysis. Cent Eur J Immunol. 2019;44 (2):159-173. doi:10.5114/ceji.2019.87067

26. Xu D, Yi H, Yu S, Li X, Qiao Y, Deng W. Association of complement C5 gene polymorphisms with proliferative diabetic retinopathy of type 2 diabetes in a Chinese Han Population. PLoS One. 2016;11 (3):e0149704. doi:10.1371/journal.pone.0149704

27. Giles JL, Choy E, van den Berg C, Morgan BP, Harris CL. Functional analysis of a complement polymorphism (rs17611) associated with rheumatoid arthritis. $J$ Immunol. 2015;194(7):3029-3034. doi:10.4049/jimmunol.1402956

28. Guo L, Zheng L, Guo X, Chang Y, Zhou X, Sun Y. Single-nucleotide polymorphism rs17611 of complement component 5 shows association with ischemic stroke in Northeast Chinese Population. Genet Test Mol Biomarkers. 2016;20(12):766-770. doi:10.1089/ gtmb.2016.0125

29. Woehrl B, Brouwer MC, Murr C, et al. Complement component 5 contributes to poor disease outcome in humans and mice with pneumococcal meningitis. J Clin Invest. 2011;121(10):3943-3953. doi:10.1172/JCI57522
30. Singer M, Deutschman CS, Seymour CW, et al. The third international consensus definitions for sepsis and septic shock (sepsis-3). JAMA. 2016;315(8):801-810. doi:10.1001/jama.2016.0287

31. Zhang W, Lu F, Xie Y, et al. miR-23b negatively regulates sepsis-induced inflammatory responses by targeting ADAM10 in human THP-1 monocytes. Mediators Inflamm. 2019;2019:5306541. doi:10.1155/2019/5306541

32. Schaeffer V, Cuschieri J, Garcia I, et al. The priming effect of C5a on monocytes is predominantly mediated by the p38 MAPK pathway. Shock. 2018;50(1):127.

33. Gotts JE, Matthay MA. Sepsis: pathophysiology and clinical management. BMJ. 2016;353:i1585. doi:10.1136/bmj.i1585

34. Hajishengallis G, Reis ES, Mastellos DC, Ricklin D, Lambris JD. Novel mechanisms and functions of complement. Nat Immunol. 2017;18(12):1288-1298. doi:10.1038/ni.3858

35. Mollnes TE, Huber-Lang M. Complement in sepsis-when science meets clinics. FEBS Lett. 2020;594(16):2621-2632. doi:10.1002/ 1873-3468.13881

36. Reis ES, Mastellos DC, Hajishengallis G, Lambris JD. New insights into the immune functions of complement. Nat Rev Immunol. 2019;19(8):503-516. doi:10.1038/s41577-019-0168-x

37. Riedemann NC, Guo RF, Ward PA. A key role of C5a/C5aR activation for the development of sepsis. J Leukoc Biol. 2003;74 (6):966-970. doi:10.1189/jlb.0403137

38. Hoehlig K, Maasch C, Shushakova N, et al. A novel C5a-neutralizing mirror-image (1-)aptamer prevents organ failure and improves survival in experimental sepsis. Mol Ther. 2013;21(12):2236-2246. doi: $10.1038 / \mathrm{mt} .2013 .178$

39. Rittirsch D, Flierl MA, Nadeau BA, et al. Functional roles for C5a receptors in sepsis. Nat Med. 2008;14(5):551-557. doi:10.1038/ $\mathrm{nm} 1753$

40. Vollrath JT, Marzi I, Herminghaus A, Lustenberger T, Relja B. Posttraumatic sepsis is associated with increased C5a and decreased TAFI levels. J Clin Med. 2020;9(4):1230. doi:10.3390/jcm9041230

41. Gressner OA, Koch A, Sanson E, Trautwein C, Tacke F. High C5a levels are associated with increased mortality in sepsis patients-no enhancing effect by actin-free Gc-globulin. Clin Biochem. 2008;41 (12):974-980. doi:10.1016/j.clinbiochem.2008.05.005

42. Riedemann NC, Guo RF, Bernacki KD, et al. Regulation by C5a of neutrophil activation during sepsis. Immunity. 2003;19(2):193-202. doi:10.1016/S1074-7613(03)00206-1

43. Xu D, Hou S, Jiang Y, et al. Complement C5 gene confers risk for acute anterior uveitis. Invest Ophthalmol Vis Sci. 2015;56 (8):4954-4960. doi:10.1167/iovs.15-16645

44. Wu H, Weng Y, Zheng L, et al. Polymorphism of the complement 5 gene is associated with large artery atherosclerosis stroke in Chinese patients. Arq Neuropsiquiatr. 2016;74(11):881-886. doi:10.1590/ 0004-282x20160139

45. Hoke M, Speidl W, Schillinger M, et al. Polymorphism of the complement 5 gene and cardiovascular outcome in patients with atherosclerosis. Eur J Clin Invest. 2012;42(9):921-926. doi:10.1111/ j.1365-2362.2012.02669.x

46. Yan C, Gao H. New insights for $\mathrm{C} 5 \mathrm{a}$ and $\mathrm{C} 5$ a receptors in sepsis. Front Immunol. 2012;3:368. doi:10.3389/fimmu.2012.00368

47. Ward PA. Role of C5 activation products in sepsis. Sci World J. 2010;10:2395-2402. doi:10.1100/tsw.2010.216

48. Guo RF, Riedemann NC, Ward PA. Role of C5a-C5aR interaction in sepsis. Shock. 2004;21(1):1-7. doi:10.1097/01. shk.0000105502.75189.5e

49. Höpken U, Mohr M, Strüber A, et al. Inhibition of interleukin-6 synthesis in an animal model of septic shock by anti-C5a monoclonal antibodies. Eur J Immunol. 1996;26(5):1103-1109. doi:10.1002/ eji. 1830260522

50. Riedemann NC, Guo RF, Hollmann TJ, et al. Regulatory role of C5a in LPS-induced IL-6 production by neutrophils during sepsis. FASEB J. 2004;18(2):370-372. doi:10.1096/fj.03-0708fje 
51. Khameneh HJ, Ho AW, Laudisi F, et al. C5a regulates IL-1 $\beta$ production and leukocyte recruitment in a murine model of monosodium urate crystal-induced peritonitis. Front Pharmacol. 2017;8:10. doi:10.3389/fphar.2017.00010

52. Seow V, Lim J, Iyer A, et al. Inflammatory responses induced by lipopolysaccharide are amplified in primary human monocytes but suppressed in macrophages by complement protein C5a. J Immunol. 2013;191(8):4308-4316. doi:10.4049/jimmunol.1301355
53. Ehrnström B, Kojen JF, Giambelluca M, et al. TLR8 and complement C5 induce cytokine release and thrombin activation in human whole blood challenged with gram-positive bacteria. J Leukoc Biol. 2020;107(4):673-683. doi:10.1002/JLB.3A0120-114R

\section{Publish your work in this journal}

The Journal of Inflammation Research is an international, peerreviewed open-access journal that welcomes laboratory and clinical findings on the molecular basis, cell biology and pharmacology of inflammation including original research, reviews, symposium reports, hypothesis formation and commentaries on: acute/chronic inflammation; mediators of inflammation; cellular processes; molecular mechanisms; pharmacology and novel anti-inflammatory drugs; clinical conditions involving inflammation. The manuscript management system is completely online and includes a very quick and fair peerreview system. Visit http://www.dovepress.com/testimonials.php to read real quotes from published authors.

Submit your manuscript here: https://www.dovepress.com/journal-of-inflammation-research-journal 